\title{
ANÁLISE DA PAISAGEM DA RESERVA EXTRATIVA MARINHA DELTA DO PARNAÍBA NA PERSPECTIVA GEOSSISTÊMICA
}

\author{
LANDSCAPE ANALYSIS OF THE DELTA MARINE EXTRACTIVE RESERVE OF \\ PARNAÍBA FROM A GEOSYSTEMIC PERSPECTIVE
}

\author{
ANÁLISIS DEL PAISAJE DE LA RESERVA EXTRATIVA MARINHA DELTA DO PARNAÍBA \\ DESDE LA PERSPECTIVA GEOSISTÉMICA
}

\author{
Glácia Lopes Araújo ${ }^{1}$ \\ Silvana Araújo Maciel ${ }^{2}$ \\ Edivânia Gomes de Assis Silva ${ }^{3}$
}

\begin{abstract}
Resumo
A análise da paisagem dentro de uma visão geossistêmica prioriza a identificação e caracterização dos sistemas homogêneos contidos na Reserva Extrativa Delta do Parnaíba - RESEX, onde cada sistema é integrado por variados componentes naturais que estabelecem relações entre si, as quais possibilitam fluxos contínuos de matéria e energia. Nesse sentido, este artigo teve como objetivo uma análise sistematizada e estruturada da paisagem dessa Unidade de Conservação - UC de Uso Sustentável, considerando a atuação antrópica, sob uma perspectiva geossitêmica. A pesquisa também buscou caracterizar a conformação dos canais fluviais em seus aspectos físicos e paisagísticos; diferenciar a vegetação deltaica levando em consideração suas fitofisionomias; destacar os agentes condicionantes/determinantes da localização dos campos de dunas fixas e móveis. A pesquisa em questão é de caráter bibliográfico, tendo como fonte principal livros e periódicos, além de observação in loco para registro fotográfico das características do objeto de estudo. A análise da paisagem da área de estudo permitiu concluir que a redução da cobertura vegetal contribui para acelerar os processos erosivos nos canais fluviais e para o consequente assoreamento do leito dos rios. Constatou-se ainda que os manguezais têm grande importância ecológica e sobretudo econômica para os ribeirinhos do Delta do Parnaíba.
\end{abstract}

Palavras-chave: Paisagem. Reserva extrativa. Geossistema.

\begin{abstract}
The landscape analysis in a geosystemic perspective prioritizes the identification and characterization of homogeneous systems located in the Delta Extractive Reserve of Parnaíba - RESEX where each system is composed of several natural components that have mutual relations, which enable continuous flows of matter and energy. In this sense, this article aimed at a systematized and structured analysis of the landscape of this Conservation Unit - CU of Sustainable Use, considering the anthropic action, from a geosemic perspective. The research also sought to characterize the conformation of river channels in their physical and landscape aspects; differentiate deltaic vegetation considering its phytophysiognomies; highlight the conditioning/determining agents of the location of fixed and mobile dune fields. The research in question is bibliographic in nature, having as main source books and journals, in addition to observation on the spot for photographic recording of the characteristics of the object of study. The analysis of the landscape of the study area allowed us to conclude that the reduction of vegetation cover contributes to accelerate the erosive processes in the river channels and to the consequent silting of the riverbed. It was also found that mangroves have great ecological and especially economic importance for the riverside of the Parnaíba Delta.
\end{abstract}

Keywords: Landscape. Extractive Reserve. Geosystem.

\section{Resumen}

\footnotetext{
1 Universidade Federal do Piauí - UFPI, especialista em Gestão Ambiental e mestranda em Geografia. E-mail: glacialopestutoria@gmail.com.

${ }^{2}$ Universidade Federal do Piauí - UFPI, especialista em Gerenciamento de Recursos Ambientais e mestranda em Geografia

${ }^{3}$ Universidade Federal do Piauí - UFPI, Doutora em Geografia. E-mail: edvania@ufpi.edu.br.
} 
El análisis del paisaje desde una perspectiva geosistémica le da prioridad a la identificación y caracterización de los sistemas homogéneos contenidos en la Reserva Extractiva Delta do Parnaíba - RESEX, en donde cada sistema está integrado por variados componentes naturales que establecen relaciones entre ellos, las cuales posibilitan flujos continuos de materia y energía. En este sentido, este artículo tuvo como objetivo el análisis sistematizado y estructurado del paisaje en esta Unidad de Conservación - UC de Uso Sostenible, considerándose la actuación antrópica desde una perspectiva geosistémica. La investigación también buscó caracterizar la conformación de los canales fluviales en sus aspectos físicos y paisajísticos; diferenciar la vegetación del delta teniendo en cuenta sus fitofisionomías; destacar los agentes condicionantes/determinantes de la ubicación de los campos de dunas fijas y móviles. La investigación en cuestión es de carácter bibliográfico, asume como fuente principal libros y artículos especializados, además de observación in loco para registro fotográfico de las características del objeto de estudio. El análisis del paisaje del área de estudio permitió concluir que la reducción de la cubierta vegetal contribuye para acelerar los procesos erosivos en los canales fluviales y para la consecuente sedimentación del cauce de los ríos. Se constató además que los manglares tienen gran importancia ecológica y sobre todo económica para los ribereños del Delta do Parnaíba.

Palabras-clave: Paisaje. Reserva Extractiva. Geosistema.

\section{Introdução}

A paisagem é uma importante categoria de análise na Geografia, e assim como a definição do objeto de estudo desta ciência percorreu um longo caminho, o conceito de paisagem, e, portanto, a maneira como ela é analisada e interpretada, também oscilou muito ao longo da evolução do pensamento geográfico. De acordo com Gomes (1997), os estudos das relações entre homem e natureza e as suas representações sob a forma de paisagens, tem como ponto de partida para a Geografia, as obras de Humboldt e Ritter. Ainda de acordo com Gomes:

Destaca-se o aporte de Carl Ritter, fundamental para o desenvolvimento sistémico da Antropogeografia física. Antropogeografia, ramo do conhecimento aprofundado por Ratzel, [...]. Com esse trabalho são antecipados questionamentos sobre os determinantes na relação homem e natureza, e elaboradas as primeiras representações de paisagem segundo a cultura instituída, e com o aporte da argumentação científica (GOMES, 1997, p. 25).

Segundo Troppmair e Galina (2006), com o passar do tempo essa visão integradora nos estudos geográficos cedeu lugar a divisões e ao surgimento de novas disciplinas no âmbito da Geografia; foi retomada apenas na década de 30, quando ressurge, com os biólogos, o pensamento integrado e sistêmico, e se firma a partir daí em todas as ciências a visão de relação e dinâmica para a análise dos fenômenos. É dentro dessa visão integradora e sistêmica que aqui se pretende pautar esse estudo sobre paisagem.

Nesse sentido, Bertrand (2004) considera que

a paisagem não é a simples adição de elementos geográficos disparatados. É uma determinada porção do espaço, resultado da combinação dinâmica, portanto instável, de elementos físicos, biológicos e antrópicos que, reagindo dialeticamente uns sobre 
os outros, fazem da paisagem um conjunto único e indissociável, em perpétua evolução (BERTRAND, 2004, p. 141)

Bertrand (2004) adota uma taxonomia das paisagens classificando-as em seis níveis temporo-espaciais; de uma parte a zona, o domínio e a região; de outra parte, o geosistema, o geofácies e o géotopo. Cada uma das unidades taxonômicas propostas é analisada à luz da abordagem sistêmica, considerando a exploração biológica, o potencial ecológico e a ação antrópica, o que pressupõe o emprego da abordagem sistêmica. Devem ser caracterizadas a partir da morfodinâmica da paisagem; esta dinâmica se define pela relação morfogênese e pedogênese, que associa diversos componentes da dinâmica e os fluxos de energia e matéria no meio ambiente.

Para Odum e Barrett (2007), um sistema é um conjunto de componentes que interagem regularmente de forma interdependente, formando um todo unificado. No mesmo sentido, Bertalanffy (2015) afirma que um sistema pode ser definido como um complexo de elementos em interação, podendo se caracterizar como um sistema fechado (aqueles que são considerados como isolados do seu ambiente) ou como um sistema aberto (aqueles onde se mantêm constantes os fluxos de matéria e energia).

Segundo Tricart (1977), um sistema é um conjunto de fenômenos que se apresentam segundo fluxos de matéria e energia; cada um dos fenômenos incorporados em um sistema, geralmente, pode ser analisado ele mesmo como um sistema, que convencionalmente se denomina subsistema. Para Tricart, o conceito de sistema é, atualmente, o melhor instrumento lógico de que dispomos para estudar problemas do meio ambiente; o autor desenvolveu sua metodologia baseada no estudo da dinâmica dos ecótopos, que ele chama de ecodinâmica.

Ainda de acordo com Tricart (1977), as unidades ecodinâmicas são classificadas em meios estáveis, meios intergrades e os fortemente instáveis. Esta classificação se dá de acordo com a relação de morfogênese e pedogênese, ou seja, as áreas estáveis apresentam uma maior cobertura vegetal e dissecação moderada dos processos morfogenéticos, enquanto os meios intergrades apresentam um balanço entre a morfogênese e a pedogênese; já os meios fortemente instáveis apresentam solos rasos, inexistência de cobertura vegetal densa, planícies e fundos de vales sujeitos a inundações. Os meios instáveis são mais susceptíveis aos processos erosivos devido ao fato de que o processo morfogenético atua com maior intensidade na paisagem.

Vale ressaltar que Tricart não negligencia o papel das sociedades humanas em seus estudos; para ele, o homem participa dos ecossistemas em que vive, modificando-os; por sua vez, os ecossistemas reagem determinando algumas adaptações do homem. Para Tricart 
(1977), as interações são permanentes e intensas, qualquer que seja o nível de desenvolvimento técnico da sociedade humana.

Considerando a afirmativa de Tricart de que a abordagem sistêmica e a visão ecodinâmica das paisagens são, atualmente, os melhores instrumentos de que dispomos para estudar problemas do meio ambiente, passaremos a analisar a paisagem da Reserva Extrativista Marinha do Delta do Parnaíba , como um sistema aberto caracterizado por apresentar extensas planícies flúvio-marinhas, cortadas por uma rede de canais formadores das ilhas do delta, resultantes do processo de acumulação flúvio-marinha onde se interrelacionam processos naturais e antrópicos.

\section{Materiais e métodos}

\subsection{Descrição da área de estudo}

De acordo com a Avaliação Ambiental Estratégica Nacional do Estado do Piauí, Polo Costa do Delta e Polo das Origens, realizada pelo Programa Nacional de Desenvolvimento do Turismo - PRODETUR (2012), o litoral do Piauí possui uma paisagem complexa composta por cerrado e caatinga, que compõem uma área de transição e sistemas marinhos, onde coexistem diversos ecossistemas com suas complexidades, formados por extensas planícies flúvio-marinhas rodeadas por dunas e lagoas, manguezais, igarapés e variada fauna. O relevo do Delta do Parnaíba apresenta formações do Planalto Central Oriental da Bacia do Maranhão-Piauí, dos Baixos Planaltos do Médio-Baixo Parnaíba, dos Tabuleiros PréLitorâneos e da Planície Costeira.

A Reserva Extrativista Marinha Delta do Parnaíba (RESEX), com área de 27.022,07 hectares, foi criada pelo decreto presidencial sem número de 16 de novembro de 2000; o órgão gestor é o Instituto Chico Mendes de Conservação e Biodiversidade (ICMBio). 
Mapa 01 - Reserva Extrativista Marinha Delta do Parnaíba

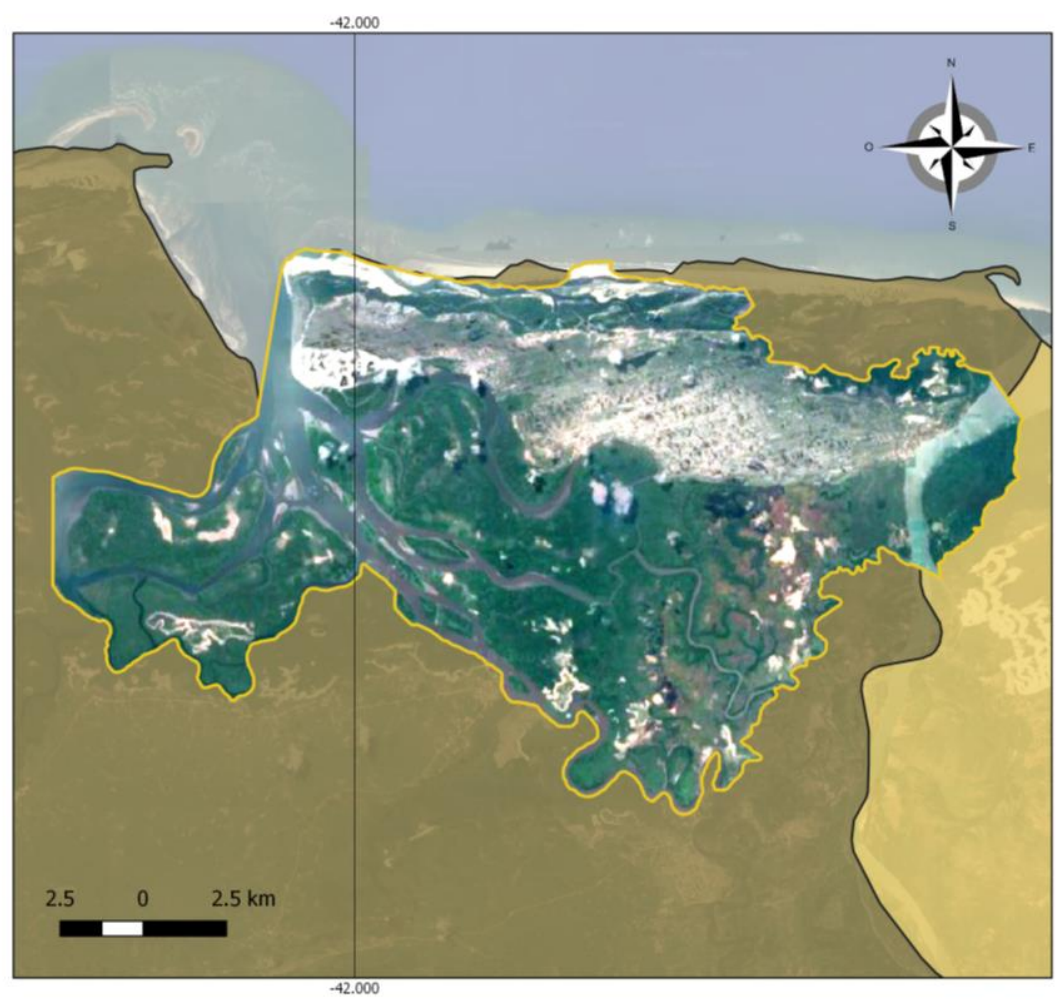

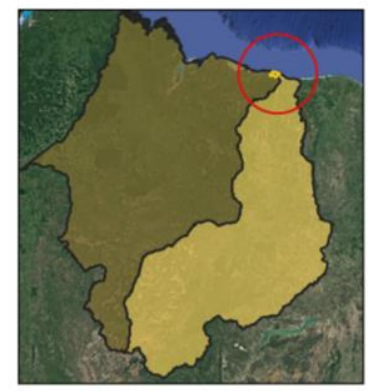

LEGENDA

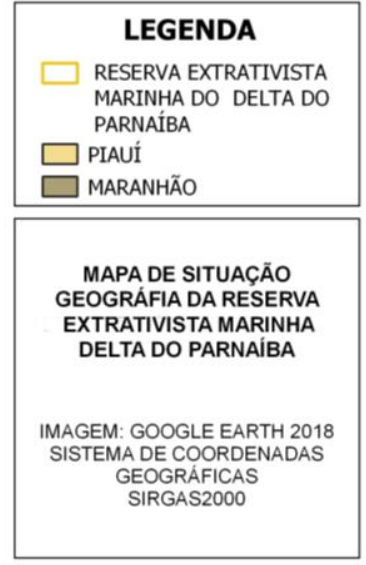

Fonte: Organização e Geoprocessamento (SANTOS, 2018a).

De acordo com o Relatório de Zoneamento Econômico Ecológico do Baixo Parnaíba, elaborado pelo Ministério do Meio Ambiente - MMA (2006, p. 5), o "complexo deltaico da foz do Parnaíba é um importante ecossistema, por sua dinâmica flúvio-marinha e por abrigar ainda importantes comunidades vegetais e animais" onde a alta biodiversidade se encontra ameaçada pelo avanço da agropecuária e da aquicultura, da fragmentação e extração desordenada de recursos naturais. Ainda de acordo com o mesmo relatório de zoneamento econômico-ecológico, o delta do Parnaíba como um todo, constitui-se em uma área ambientalmente frágil, com sistemas ambientais que variam de medianamente estável a frágil, não existindo, portanto, áreas estáveis na região. O objetivo da criação da reserva foi garantir um equilíbrio entre as práticas extrativistas na área e a conservação dos recursos naturais, conforme se pode verificar no texto legal:

Art. $2^{\circ}$ A Reserva Extrativista Marinha do Delta do Parnaíba tem por objetivo garantir a exploração auto-sustentável e a conservação dos recursos naturais renováveis tradicionalmente utilizados pela população extrativista da área.

Art. $3^{\circ}$ A área da Reserva Extrativista, ora criada, fica declarada de interesse ecológico e social, conforme preconiza o art. $2^{\circ}$ do Decreto $\mathrm{n}^{\circ} 98.897$, de 30 de janeiro de 1990 (BRASIL, 2000).

A preocupação manifestada no decreto de criação da RESEX Marinha Delta do Parnaíba se justifica pelas características físico-naturais desse ecossistema e pelas atividades 
antrópicas nele desenvolvidas. A caracterização ambiental do delta, apresentada pelo relatório de Zoneamento Econômico Ecológico do Baixo Parnaíba e à luz das proposições de Tricart (1977) sobre a ecodinâmica das paisagens, permite inferir que a área em questão é fortemente susceptível a processos erosivos, o que revela a necessidade de soma de esforços públicos e da comunidade local no sentido de viabilizar políticas de desenvolvimento sustentável, compatíveis com a fragilidade desse geossistema.

\subsection{Metodologia}

A pesquisa em questão constitui-se basicamente em uma pesquisa bibliográfica, fundamentada principalmente em Gomes (1997); Troppmair e Galina (2006); Bertrand (2004); Tricart (1977), Costa e Cavalcante (2010), e Cunha e Guerra (2003), além da visita in loco, onde foi possível observar e registrar com fotografias as características do objeto de estudo.

Sobre a pesquisa bibliográfica Gil (2002, p. 64) destaca que:

\footnotetext{
As fontes bibliográficas mais conhecidas são os livros de leitura corrente. No entanto, existem muitas outras fontes de interesse para a realização de pesquisas, tais como: obras de referência, teses e dissertações, periódicos científicos, anais de encontros científicos e periódicos de indexação e resumo.
}

Através desse levantamento bibliográfico e visita in loco, procurou-se correlacionar estudos já realizados sobre a situação da cobertura vegetal, o processo de erosão nos canais fluviais e a mobilidade das dunas no delta do Parnaíba, procurando apresentar um enfoque geossistêmico, como forma de possibilitar uma visão mais integrada do ambiente.

\section{Resultados e discussões}

\subsection{A paisagem da Reserva Extrativista Delta do Parnaíba}

Para uma melhor compreensão das dinâmicas envolvidas no geossistema do delta do Parnaíba, passar-se-á nesse momento à caracterização dos seus principais componentes; na impossibilidade de abranger neste estudo a totalidade dos elementos, destaca-se em especial a conformação dos canais fluviais, a vegetação deltaica e a presença dos campos de dunas fixas e móveis, bem como o componente antrópico inserido nessa paisagem, caracterizado pelas práticas desenvolvidas por aqueles que residem dentro da área da Resex Marinha ou mesmo pelos indivíduos que a frequentam de forma constante ou esporádica. De acordo com o 
Relatório de Zoneamento Econômico Ecológico do Baixo Parnaíba (2006), os principais usos da terra dentro da Resex Marinha Delta do Parnaíba são a pesca, o extrativismo vegetal e de caranguejo, a rizicultura, a agricultura de subsistência, o turismo e a pecuária extensiva.

Conforme se pode observar no mapa a seguir (mapa 2), a área do delta do Parnaíba se caracteriza por apresentar extensas planícies flúvio-marinhas drenadas por uma rede de canais que podem se apresentar meandrantes e/ou anastomosados; nelas se desenvolvem áreas de mangues com uma vegetação altamente especializada, áreas de restinga, comportando ainda campos de dunas móveis e fixas, resultantes da sedimentação eólica.

Mapa 2 - Mapa de cobertura do solo - Resex Extrativista Marinha Delta do Parnaíba MA/PI

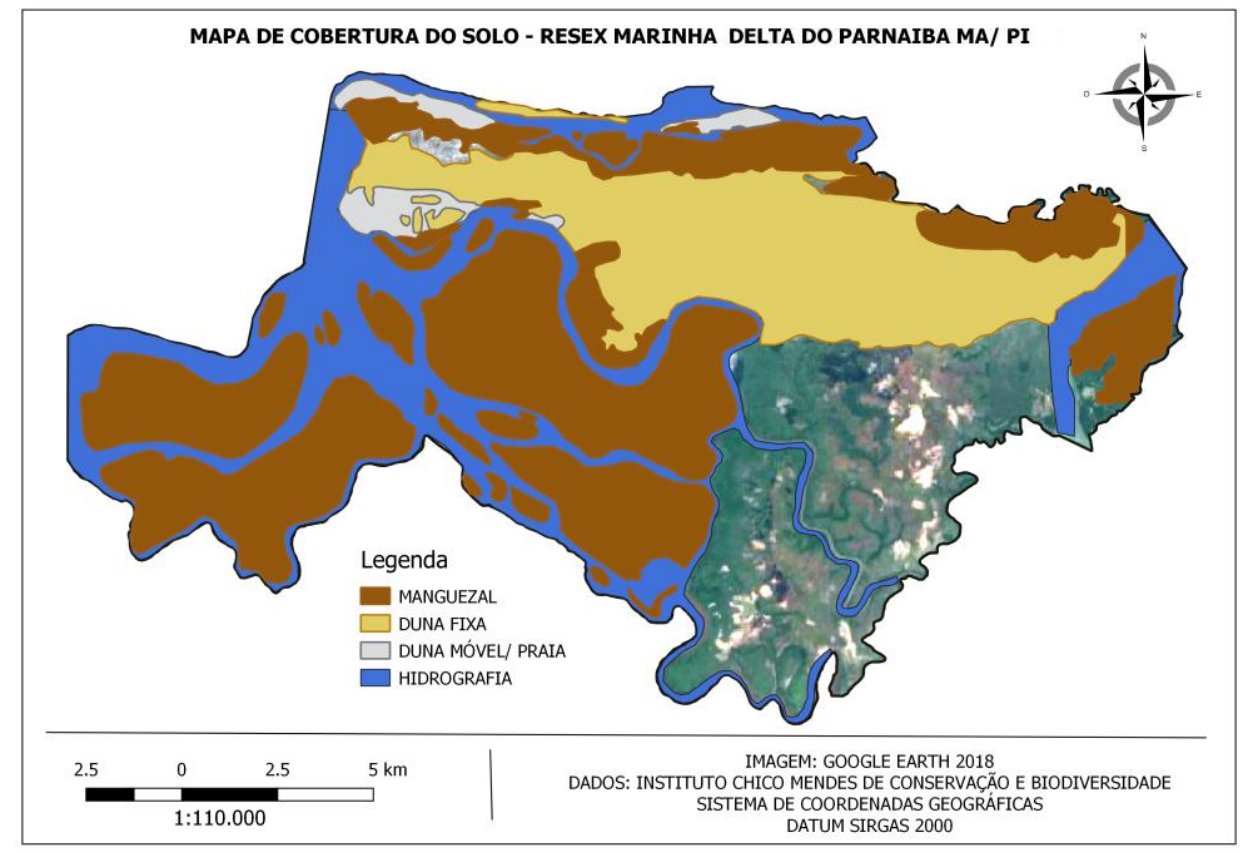

Fonte: Organização e Geoprocessamento (SANTOS, 2018b)

Cunha (2013, p. 43) define canais meandrantes como sendo aqueles que apresentam curvas sinuosas harmônicas e semelhantes entre si, ao passo que canais anastomosados são os que "apresentam grande volume de carga de fundo que, conjugado com a flutuação das descargas, ocasionam sucessivas ramificações, ou múltiplos canais que se subdividem e se reencontram, separados por ilhas assimétricas e barras arenosas”. Ainda de acordo com Cunha (2013), nos canais anastomosados, as ilhas são mais fixas no fundo do leito apesar da ação erosiva e da sedimentação, podendo também as barras serem estabilizadas pela deposição de sedimentos mais finos e/ou pela fixação de cobertura vegetal; a vegetação é um elemento que dificulta a erosão e permite a deposição de sedimentos finos. Dessa forma, pode-se depreender que a presença de vegetação no Delta é essencial para a estabilização dos canais fluviais. 
A redução da cobertura vegetal, dentro de visão apresentada por Cunha, pode se caracterizar como um grande risco ao equilíbrio dos canais do Delta do Parnaíba, uma vez que a quantidade de sedimentos carreada pelas águas dos rios está associada não somente com as suas características naturais, mas também com a maneira como o homem se relaciona com o ambiente. Ao longo dos anos essa relação tem provocado uma série de alterações nos ambientes fluviais, conhecidas como impactos ambientais.

Nesse sentido, o homem se apresenta como o principal agente transformador da natureza; ao utilizar o solo de maneira inadequada causa alterações na dinâmica natural dos rios e canais fluviais. A atuação do homem nesses ambientes, por meio do manejo inadequado, tem provocado diversos impactos ambientais (diretos e indiretos) que contribuem para aumentar os desequilíbrios.

Cunha e Guerra (2003, p. 50) fazem a seguinte observação "Os rios espelham, [...] as condições naturais e as atividades humanas desenvolvidas na bacia hidrográfica, sofrendo, [...] alterações, efeitos e/ ou impactos no comportamento da descarga, carga sólida e dissolvida, e poluição das águas".

O impacto do desmatamento sobre estes ambientes faz o solo ficar frágil e propício à erosão, o que contribui para o aumento de sedimentos na água, além da perda de habitats naturais das aves aquáticas. Tais consequências são bastante observadas nos rios brasileiros, que vêm sofrendo com o intenso desmatamento de suas áreas marginais.

De acordo com Costa e Cavalcante (2010), a vegetação do Delta do Parnaíba, sob o ponto de vista fisionômico e florístico, é composta por três estratos: arbóreo, arbustivo e gramíneo-herbáceo. O estrato arbóreo está composto principalmente pela vegetação perenifólia de mangue, com árvores que chegam a 20 metros de altura; é um estrato descontínuo, pois a presença dos cursos d'água impedem a sua continuidade; o estrato arbustivo está representado nas áreas onde ocorre a vegetação subperenifólia de dunas e possui uma altura de 3 metros; já o estrato gramíneo se caracteriza pelas espécies localizadas no campo de dunas, representadas através da vegetação pioneira e dos gramados halofíticos.

A descrição da cobertura vegetal do delta feita por Costa e Cavalcante pode ser compreendida nas imagens do quadro a seguir: 
Figura 1 - Vegetação do delta do Parnaíba

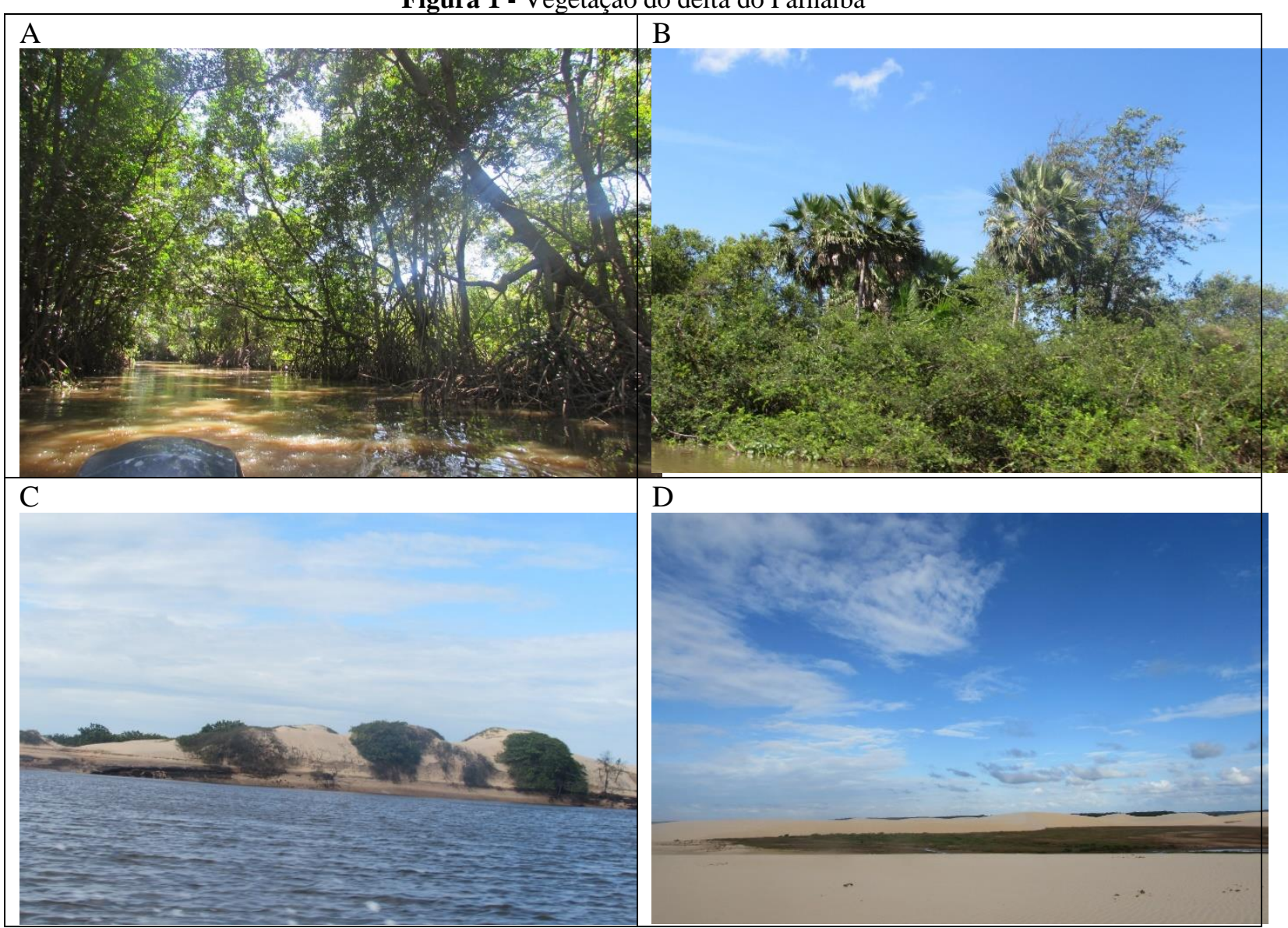

Fonte: As autoras, 2018.

$\mathrm{Na}$ imagem A tem-se a feição arbórea do mangue, ou bosque de mangue; na imagem B aparece a associação da vegetação típica de mangue com espécies como a carnaúba; a imagem $\mathrm{C}$ apresenta dunas cobertas por formação arbustiva; e a imagem $\mathrm{D}$ apresenta dunas com presença de gramíneas.

Dentro do conjunto de vegetação presente na RESEX, merece especial atenção a área de mangue, uma vez que os manguezais são um dos ecossistemas do bioma Mata Atlântica que vem sofrendo com as interferências antrópicas. O manguezal conta com uma rica e diversificada flora e fauna, além de representar um local que guarda informações históricas e socioambientais. De acordo com Alves (2001, p. 10) "estes ambientes estão presentes nas faixas tropical e subtropical do planeta, ocupando regiões tipicamente inundadas pela maré tais como: estuários, lagoas costeiras, baías e deltas".

Os manguezais possuem grande importância. Esse ecossistema é responsável pelo sequestro de carbono por área de floresta e é tão intenso quanto o que ocorre nas florestas tropicais úmidas. De acordo com o Atlas dos Manguezais do Brasil, elaborado pelo Instituto Chico Mendes de Conservação da Biodiversidade - ICMBio (2018, p. 4) "quando se 
considera o reservatório de carbono contido na biomassa acima do solo, o estoque de carbono em manguezais tropicais por unidade de área é significativamente maior que o observado em quaisquer florestas terrestres, [...]”. Os manguezais possuem, ainda, grande importância na redução da vulnerabilidade da zona costeira no que se refere às mudanças climáticas, como o regime das chuvas, alterações da temperatura, elevação na concentração de dióxido de carbono, elevação no nível do mar, tempestades e elevação das marés.

Pereira Filho e Alves (1999, apud ALVES, 2001, p. 13) afirmam que os manguezais desempenham inúmeras funções naturais, as quais têm importância ecológica e econômica, como por exemplo a retenção da linha de costa através da atuação da vegetação contra a ação erosiva das ondas e marés; a retenção de sedimentos carreados pelos rios que permite a manutenção da vegetação; ação depuradora fundamental no processo de fixação e inertização de partículas contaminantes, como metais pesados; área de concentração de nutrientes e renovação de biomassa costeira, rica em alimento; áreas de alimentação, abrigo, nidificação e repouso de aves.

As funções naturais dos manguezais lhe conferem grande importância ecológica e sobretudo econômica para o homem, o qual vem utilizando seus recursos através dos tempos. No Brasil, a ocupação dos manguezais tem contribuído para a redução de suas áreas. Para Alves (2001, p. 20) “o desmatamento em áreas de manguezais é uma das alterações ambientais mais antigas no Brasil, praticado desde o século XVI".

Conforme se observa no mapa 2, a RESEX Delta do Parnaíba também apresenta um extenso campo de dunas fixas e uma área considerável de dunas móveis, cuja presença se explica pelas condições de vento do local e pelas características dos sedimentos ali presentes, conforme explica Muehe:

Dunas costeiras se formam em locais em que a velocidade do vento e a disponibilidade de areias praiais de granulometria fina são adequadas para o transporte eólico. Estas condições são mais frequentemente encontradas em praias do tipo dissipativo a intermediário, de gradiente suave, como ocorre em quase todo o litoral do Rio Grande do Sul, em Cabo Frio, no litoral do Rio de Janeiro, em muitos locais do litoral do Maranhão, Piauí e Ceará (MUEHE, 2013, p. 298).

Na Avaliação Ambiental Estratégica do PRODETUR (2012), as dunas controlam, em grande parte, a dinâmica dos demais sistemas associados, pois no processo de formação e migração, as dunas móveis avançam sobre a vegetação, soterrando restingas, manguezais e matas ciliares das planícies fluviais, podendo também ao longo desse processo alterar o curso dos rios, formar ou alterar lagoas e atingir também ocupações humanas. 
No caso específico do campo de dunas presente na Resex Marinha Delta do Parnaíba, observa-se que este se compõe principalmente de dunas fixas (conforme figura 2), graças à presença de vegetação que reduz a mobilidade dos sedimentos provocada pela ação eólica, conforme enfatiza a Avaliação Ambiental Estratégica do Prodetur Nacional do Estado do Piauí, Polo Costa do Delta e Polo das Origens.

\begin{abstract}
Outro ponto fundamental na movimentação das dunas é a intensidade da energia do vento (wind power), que é também um fator limitante no crescimento da vegetação em dunas. As interações biológicas e físicas nas dunas são na sequência desenvolvidas por estresse, o que demonstra que a duna pode ser vegetalizada quando a energia do vento for baixa. Conforme o crescimento da vegetação, é necessário que o vento exerça uma pressão maior que a anterior para destruir a vegetação e reativar as dunas (PRODETUR, 2012, p. 78).
\end{abstract}

Dessa forma, entende-se que a remoção da cobertura vegetal pode ser fator determinante para a reativação das dunas que atualmente são fixas, fazendo com que haja alteração no sistema como um todo. Vale ressaltar que a presença do campo de dunas não representa por si só um fator de risco de desequilíbrio ambiental, tornando-se um problema apenas quando a ação antrópica potencializa ou acelera a dinâmica natural dos campos de duna, conforme enfatiza a Avaliação Ambiental Estratégica do Prodetur Nacional do Estado do Piauí, Polo Costa do Delta e Polo das Origens.

\footnotetext{
Vale salientar que as dunas nessa região exercem funções ambientais bastante importantes: estabilizam a linha de costa, protegem o lençol freático, constituem uma barreira natural contra as ressacas do mar e são habitat para diferentes espécies da fauna e da flora. Além desses aspectos extremamente relevantes, a movimentação das dunas produz um ambiente singular com belas paisagens de relevante interesse à visitação turística. No caso da retirada da vegetação, há comprometimento da sua mobilidade, o que muitas vezes pode levar a um rápido avanço da areia sob casas e mesmo sob outros ambientes, transformando dunas já estabilizadas em móveis novamente. (PRODETUR, 2012, p. 79).
}

Dessa forma, a presença das dunas é fator positivo, tanto do ponto de vista ambiental quanto econômico e social, pois produz uma paisagem atrativa para a atividade turística e desempenha funções ambientais importantes; no entanto, faz-se necessário um eficiente plano de zoneamento econômico-ecológico para que as atividades antrópicas não venham a alterar a dinâmica natural de movimentação das dunas.

\title{
4 Considerações finais
}

O homem tem utilizado o meio ambiente como algo eterno, diferentemente do que rege a Constituição Federal, contribuindo assim para uma degradação generalizada dos 
recursos da natureza. Essa realidade é urgente e pede um planejamento físico que englobe as questões econômicas, sociais e ambientais. É necessário, portanto, repensar o modelo econômico adotado pelas sociedades, assim como os diferentes usos dos recursos do meio ambiente, de forma a encontrar soluções adequadas para um perfeito equilíbrio entre a natureza e o homem. A análise da paisagem em uma perspectiva geossitêmica permite uma maior compreensão das inter-relações entre natureza e sociedade; é, portanto, uma ferramenta eficaz para elaboração de planos de manejo que venham a garantir o tão desejado desenvolvimento sustentável.

Nesse sentido, o presente estudo procurou demonstrar que a paisagem da Reserva Extrativista Marinha Delta do Parnaíba se constitui em um geossistema frágil, que pelas suas características naturais está fortemente propenso a processos erosivos; nele, a retirada da cobertura vegetal por meio da ação antrópica pode vir a alterar significativamente o equilíbrio do geossistema como um todo, inclusive comprometendo o modo de vida das comunidades residentes na área da reserva, à medida que essa remoção acelera o processo de erosão nos canais fluviais e potencializa a mobilidade das dunas. Esse fenômeno pode provocar um forte processo de assoreamento dos canais, comprometendo a navegação e o abastecimento hídrico das comunidades inseridas na reserva, bem como reduzir outros serviços ambientais oferecidos pelo sistema deltaico.

O estudo revela ainda que a preservação dos manguezais é uma peça fundamental para garantir o equilíbrio geossitêmico do delta do Parnaíba, pois eles proporcionam serviços ambientais extremamente importantes, como o sequestro de carbono, a retenção de sedimentos carregados pelos rios e canais fluviais, além de oferecer importantes recursos extrativos de grande importância econômica para região.

\section{Referências}

ATLAS DOS MANGUEZAIS DO BRASIL. Atlas dos manguezais do Brasil. Instituto Chico Mendes de Conservação da Biodiversidade. Brasília: ICMBio, 2018. Disponível em: https://www.icmbio.gov.br/portal/images/stories/manguezais/atlas_dos_manguezais_do_brasi 1.pdf. Acesso em: 28 mai. 2019.

ALVES, Jorge Rogério Pereira (org.). Manguezais: educar para proteger. Rio de Janeiro: FEMAR; SEMADS, 2001. Disponível em: https://www.mma.gov.br/estruturas/sqa_pnla/_arquivos/manguezais.pdf. Acesso em: 28 mai. 2019.

BRASIL. Decreto de 16 de novembro de 2000. Cria a Reserva Extrativista Marinha do Delta do Parnaíba, no Município de Ilha Grande de Santa Isabel, Estado do Piauí, e nos Municípios 
de Araióses e Água Doce, Estado do Maranhão, e dá outras providências. Brasília, Diário Oficial, 2000.

BERTALANFFY, L. V. Teoria geral dos sistemas: fundamentos, desenvolvimento e aplicações. 8. ed. Petrópolis: Vozes, 2015.

BERTRAND, Georges. Paisagem e geografia física global: um esboço metodológico. Revista RA'E GA, Curitiba, n. 8, p. 141-152, 2004. (Editora UFPR).

COSTA, Jorge Luis Paes de Oliveira; CAVALCANTE, Agostinho Paula Brito. Fitogeografia da planície deltaica do Rio Parnaíba, Piauí/Maranhão - Brasil: Análise da distribuição das espécies e interferência antrópica. Observatorium: revista eletrônica de Geografia, Piauí Maranhão, v. 2, n. 4, p. 84-92, jul. 2010.

CUNHA, Sandra Baptista da. Geomorfologia fluvial. In: GUERRA, Antonio José Teixeira; CUNHA, Sandra Baptista da (org.). Geomorfologia: uma atualização de bases e conceitos. 12. ed. Rio de Janeiro: Bertrand Brasil, 2013.

CUNHA, Sandra Baptista da; GUERRA, Antônio José Teixeira (org.). A questão ambiental: diferentes abordagens. 1. ed. Rio Janeiro: Bertrand, Brasil, 2003.

GIL, Antonio Carlos. Como Elaborar Projetos de Pesquisa. 4. ed. São Paulo: Atlas, 2002. $175 \mathrm{p}$.

GOMES, Edvânia Torres Aguiar. Recortes de paisagens na cidade do Recife: uma abordagem geográfica (1997). 1997. Tese (Doutorado em geografia) - Universidade de São Paulo, USP, 1997.

MUEHE, D. Geomorfologia costeira. In: GUERRA, A. J. T.; CUNHA, S. B. (org.). Geomorfologia: uma atualização de bases e conceitos. 12. ed. Rio de Janeiro: Bertrand Brasil, 2013.

ODUM, E. P.; BARRETT, G. W. Fundamentos de ecologia. 5. ed. São Paulo: Thompson Learning, 2007.

MMA. Ministério do Meio Ambiente. Relatório de zoneamento econômico ecológico do baixo Parnaíba. Brasília: Ministério do Meio Ambiente, 2006. Disponível em: https://www.mma.gov.br/estruturas/PZEE/_arquivos/baixopar_relatorio_completo.pdf. Acesso em: 28 mai. 2019.

PRODETUR. Ministério do Turismo. Elaboração da avaliação ambiental estratégica do Prodetur nacional no estado do Piauí. Piauí: Prodetur, 2012. Disponível em: http://www.turismo.gov.br/sites/default/turismo/DPROD/AVALIACAO_AMBIENTAL/PI/A AE_PI.pdf. Acesso em: 28 mai. 2019.

SANTOS, Mariana Rodrigues Oliveira dos. Mapa de localização geográfica da Reserva Extrativista Marinha do Delta do Parnaíba MA/PI. 2018a.

SANTOS. Mariana Rodrigues Oliveira dos. Mapa de cobertura do solo da Reserva Extrativista Marinha do Delta do Parnaíba MA/PI. 2018b. 
SCHAEFFER-NOVELLI, Y. Relatório técnico: avaliação e ações prioritárias para a conservação da biodiversidade da zona costeira e marinha. Disponível em: http://rodadas.anp.gov.br/arquivos/Round8/sismica_R8/Bibliografia/MMA2002.PDF. Acesso em: 27 jun. 2018.

TRICART, Jean. Ecodìnâmica. Rio de Janeiro: IBGE; Diretoria Técnica; SUPREN, 1977. Disponível em: https://biblioteca.ibge.gov.br/visualizacao/monografias/GEBIS\%20\%20RJ/ecodinamica.pdf. Acesso em: 27 jun. 2018.

TROPPMAIR, Helmut; GALINA, Marcia Helena. Geossistemas. Rev. Mercator, Fortaleza, v. 5, n. 10, p 79-90, nov. 2006. Disponível em:

http://www.mercator.ufc.br/mercator/article/view/69. Acesso em: 15 jun. 2019. 